Essai sur les fondements de la géométrie Euclidienne Par Julien Malengreau. Pp. 311. (Lausanne et Genène: Payot et Cie., 1938.) 8 francs.

$\mathrm{M}$ MALENGREAU conceives the object of a - geometrical treatise to be that of investigating the point-aggregates of a space which has been generated by the help of appropriate postulates. In the present essay, he has set himself the task of generating the most elementary space which can be the object of Euclidean geometry, where Euclidean space is understood as that space which corresponds to the conditions of our environment according to such immediate verifications as we possess. The method whereby M. Malengreau obtains this elementary Euclidean space is based upon the generation of aggregates containing an indefinite number of points, from those containing only a definite number. Such a process necessitates the consideration of all those intermediary aggregates which are of use in classifying the new points as they are obtained. But M. Malengreau is careful to introduce as few new definitions as possible; although he invents several new terms to apply to aggregates which are termed differently in classical geometry, and in some cases, uses the familiar terms in a different sense from that of classical geometry.

From the outset, his method differs radically from that of classical geometry, the definitions, postulates and theorems being introduced in logical order according to the indispensability of the ideas which they define and explain, and then only to the extent necessary to enable them to generate a new fundamental aggregate. But M. Malengreau points out that it is not possible to pass from an aggregate of lower to one of higher order, until the extensions of the members of the former in order and magnitude have been determined.

M. Malengreau maintains that the elementary space generated by his method is equal in experimental value to the general Euclidean space of classical geometry; and his treatment is original enough for one to anticipate with interest the general treatise on geometry which he is planning and to which this essay serves as an introduction.

\section{Hydrophobic Colloids}

Symposium on the Dynamics of Hydrophobic Sus. pensions and Emulsions held at Utrecht on the 5th and 6 th November 1937, under the auspices of the Colloidchemistry Section of the "Nederlandsche Chemische Vereeniging". Pp. 181. (Amsterdam : D.B. Centen's Uitgevers-Maatschappij, 1938.) 4 florins.

$\mathrm{T}$ HIS book forms a testimonial to the work of the Dutch school on hydrophobic colloidal solutions. It contains a number of papers on the electrical double layer, including one of special importance by H. C. Hamaker, who discusses stability in terms of potential curves. Ionic exchange is then discussed and the book ends with two papers on emulsions. It should be read by all workers on colloids, but with certain reservations. The best comment is provided by Prof. Kruyt at the end of his introduction. He says: "To-day colloid chemistry floats in water! All our results are confined to an ionising intermicellar liquid, and I can scarcely think of any satisfactory way of extending these discussions to non-aqueous systems." But why try ? It must be realized that colloidal solutions fall into two main classes. First there are those the stability of which is due to an ionized surface layer, which may be formed by adsorption of ions as in hydrophobic sols, or which may be due to the presence in the particles of ionizable groups. The particle may be a polymer-molecule or a micelle, for example, proteins and soaps. Secondly, there is the rapidly growing class of substances which form stable solutions because they are soluble in the solvent and which are colloidal because of their large molecular weights, for example, rubber and the polymers generally. There is no reason why this dualism should be more disturbing in two-dimensional chemistry than in ordinary three-dimensional chemistry. It is not a bar to progress, but a clear indication of how far a particular line of attack can be followed profitably.

A. S. C. L.

Discarnate Influence in Human Life:

a Review of the Case for Spirit Intervention. By Ernesto Bozzano. Translated by Isabel Emerson. (Library of the International Institute for Psychical Research, Vol. 1.) Pp. xiv +274. (London: International Institute for Psychical Research; John M. Watkins, n.d.) $88.6 d$.

T $N$ this volume, Signor Bozzano, one of the most prolific of Italian writers on psychical research, sums up the conclusions to which he has been led in the course of many years of attention to this subject. The book will be of some considerable interest to spiritualists, since it attempts to deal in detail with the difficulty of combining, in one so-called explanation, phenomena where resort to a spiritistic hypothesis is clearly unnecessary, and other manifestations where the influence of the discarnate might to some minds be considered obvious.

Signor Bozzano advances the view that it is not a situation where the choice is between what he calls "animism" and spiritualism, but that it is one where the two are combined and interlinked to such an extent that it may be said that animism proves spiritualism. The subliminal processes are, to Signor Bozzano, the senses of the spirit still incarnate, which are only later to emerge and function in the environment proper to them. Thus instead of being an all-sufficient explanation of "psychic" phenomena they can be regarded as pointers to the only true explanation, namely, the activity of spirits still incarnate, which, when released from the body at death, fulfil their destiny in spiritual realms.

Although the theory will scarcely be considered by those to whom the existence of 'psychic' phenomena is still in doubt, it will certainly be discussed at length by psychical researchers generally, to whom this book, so well translated by Isabel Emerson, can therefore be commended. 